\title{
COVID-19 Presenting as Severe Rhabdomyolysis With Normal Renal Function
}

\author{
Akshay Shanbhag ${ }^{1}$, Pritika S. Manaktala ${ }^{2}$, Hira Rizvi ${ }^{2}$, Kevin Frey ${ }^{2}$, Rama Narayanan ${ }^{2}$ \\ 1. Internal Medicine/Geriatrics, Beth Israel Deaconess Medical Center, Harvard Medical School, Boston, USA 2. \\ Internal Medicine, Canton Medical Education Foundation, Canton, USA
}

Corresponding author: Akshay Shanbhag, ashanbhag15@gmail.com

\begin{abstract}
Coronavirus disease 2019 (COVID-19) continues to increase morbidity and mortality. Early recognition of symptoms, along with prompt intervention, is required to improve patient outcomes. COVID-19 can have a multifaceted presentation, which can be a diagnostic challenge. Here, we report the first case of COVID-19 presenting as severe rhabdomyolysis with creatine kinase $>500,000 \mathrm{U} / \mathrm{L}$ with normal renal function in a young adult.
\end{abstract}

Categories: Internal Medicine, Infectious Disease

Keywords: covid-19, rhabdomyolysis, normal renal function

\section{Introduction}

Coronavirus disease 2019 (COVID-19) is currently a global health crisis caused by Severe Acute Respiratory Syndrome Coronavirus-2 (SARS-COV-2). Belonging to the Coronavirus family, which includes Middle East respiratory syndrome coronavirus (MERS) and severe acute respiratory syndrome coronavirus (SARS), a prompt diagnosis is required to improve patient outcomes. Common symptoms include fever, dyspnea, cough and fatigue, while less common symptoms are sputum production, headache and hemoptysis [1]. An atypical presentation can be a diagnostic challenge. Currently, there have been few reported cases of COVID-19 associated rhabdomyolysis in adults and few in pediatrics [2-10]. Here, we report the first case of COVID-19 presenting as severe rhabdomyolysis with creatine kinase $>500,000 \mathrm{U} / \mathrm{L}$ with normal renal function in a young adult.

Received 07/21/2020

Review began 07/27/2020 Review ended 07/31/2020 Published 08/04/2020

\section{(๑) Copyright 2020}

Shanbhag et al. This is an open access article distributed under the terms of the Creative Commons Attribution License CC-BY 4.0., which permits unrestricted use, distribution, and reproduction in any medium, provided the original author and source are credited.

\section{Case Presentation}

A 19-year-old African-American male with a history of anxiety, prior influenza-associated rhabdomyolysis presented to the ED with a three-day history of worsening bilateral lower extremity myalgias, associated with red-colored urine and a mild dry cough. The remaining review of systems was negative. He denied exercise intolerance and family history was unremarkable for myopathies or neuromuscular disorders. Social history was negative for alcohol, smoking or illicit drug use. He endorsed working in an extended care facility with COVID-19 patients. Believing he may have COVID-19, he presented to the ED. Vitals were normal and the physical exam was remarkable only for bilateral lower extremity tenderness. Complete blood count (CBC) showed leukopenia of $2.4 \times 10^{9} / \mathrm{L}$ (Range: $4.5-11 \times 10^{9} / \mathrm{L}$ ) with lymphocytopenia of $0.9 \times 10^{9} / \mathrm{L}$ (range: $1-4 \times$ $\left.10^{9} / \mathrm{L}\right)$. Basic metabolic panel (BMP), renal function, procalcitonin, d-dimer and ferritin were normal. Serum creatine kinase (CK) and lactate dehydrogenase (LDH) were elevated at 284,240 U/L (range: 39-308 U/L) and 2517 U/L (Range: 87-241 U/L), respectively. C-reactive protein (CRP) was elevated at $0.57 \mathrm{mg} / \mathrm{dL}$ (range: 0$0.32 \mathrm{mg} / \mathrm{dL}$ ). The liver panel showed aspartate aminotransferase (AST) and alanine aminotransferase (ALT) were elevated at $1014 \mathrm{U} / \mathrm{L}$ (range: 8-34 U/L) and $132 \mathrm{U} / \mathrm{L}$ (range: 13-61 U/L), respectively. Urine dipstick was positive for blood but negative for red blood cells (RBCs). Chest X-ray, respiratory viral panel, urine and serum toxicology screen were unremarkable (Figure 1). He was admitted for severe rhabdomyolysis and started on intravenous fluids. He tested positive for COVID-19 and we continued conservative management without antibiotics or hydroxychloroquine. Serum and urine myoglobin were elevated at 23,508 ng/ml (range: $28-72 \mathrm{ng} / \mathrm{ml}$ ) and $173 \mathrm{ng} / \mathrm{ml}$ (range: 0-13 ng/ml), respectively. Viral hepatitis panel, aldolase, thyroid-stimulating hormone (TSH), erythrocyte sedimentation rate (ESR), anti-nuclear antibody (ANA), anti-Jo-1, anti-SSA/SSB, anti-RNP, anti-dsDNA and anti-Smith antibodies were unremarkable. His myalgias continued to worsen, now involving his upper extremities. Serum CK, LDH and AST levels continuously rose, peaking at 694,200 U/L, 13,950 U/L and $2715 \mathrm{U} / \mathrm{L}$, respectively. His renal function and urine output, however, were within normal limits. His symptoms and levels started improving by day 5 with supportive care (Figure 2). Given his history and positive COVID-19 test, it supported COVID-19 presenting as rhabdomyolysis. His renal function, urine output and respiratory function, interestingly, did not deteriorate throughout his eight-day hospital course. During one of his prior hospitalizations for influenza-associated rhabdomyolysis, he underwent an evaluation for metabolic myopathy, which was unremarkable. 


\section{Cureus}

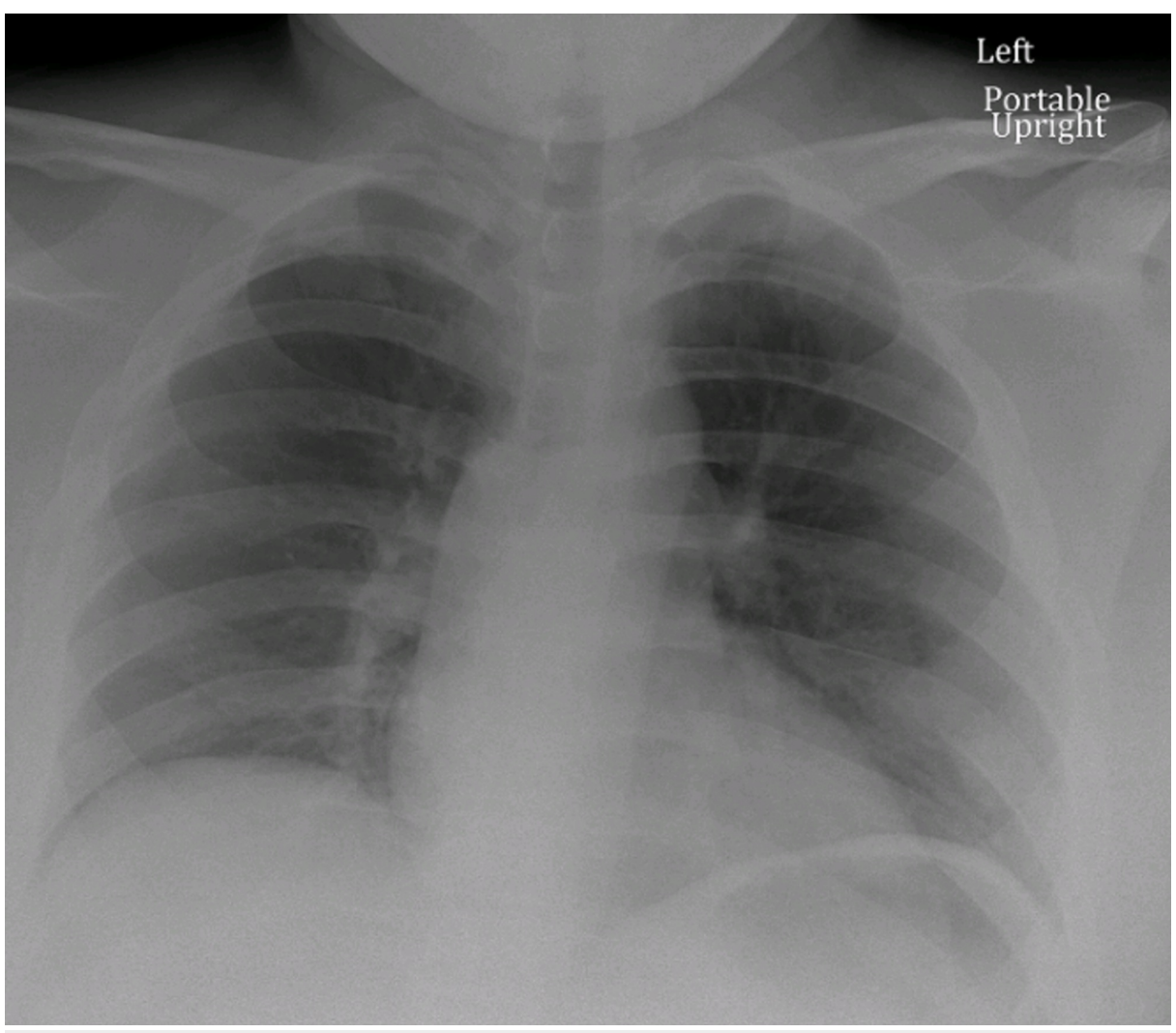

FIGURE 1: Admission chest x-ray

\begin{tabular}{|c|c|c|c|c|c|c|c|c|c|}
\hline & Day 0 & Day 1 & Day 2 & Day 3 & Day 4 & Day 5 & Day 6 & Day 7 & Day 8 \\
\hline Creatine kinase [U/L] (Range: 39-308 U/L) & & 284,240 & 316,115 & 605,600 & 694,200 & 272,946 & 157,532 & 55,605 & 18,089 \\
\hline BUN [mg/di] (Range: 7-18 mg/dl) & 10 & 9 & 8 & 11 & 12 & $" 1$ & 12 & 12 & 14 \\
\hline Creatinine $[\mathrm{mg} / \mathrm{d}]$ (Range: $0.8 \cdot 1.12 \mathrm{mg} / \mathrm{dl})$ & 0.888 & 0.982 & 0.769 & 0.674 & 0.588 & 0.704 & 0.593 & 0.612 & 0.573 \\
\hline AST [U/L] Range: $8.34 \mathrm{U} / \mathrm{L}$ ) & & 1014 & 1931 & 2551 & 2715 & 2622 & 1506 & 805 & 354 \\
\hline ALT [IU/L] Range: 13.61 U/L) & & 132 & 224 & 320 & 420 & 483 & 401 & 347 & 273 \\
\hline LDH [ULL] (Range: $87.241 \mathrm{ULL})$ & 2517 & & 9153 & 13.950 & 13,627 & 8838 & 2107 & 711 & 336 \\
\hline Serum Myoglobin [ng/m] (Range: $28.72 \mathrm{ng} / \mathrm{ml}$ ) & . & - & - & 23.508 & - & & 4420 & & - \\
\hline Urine myoglobin [ng/di] (Range: $0.13 \mathrm{ng} / \mathrm{dl}$ ) & . & & & 173 & & & & & \\
\hline
\end{tabular}

FIGURE 2: Laboratory values

\section{Discussion}

Rhabdomyolysis results from the breakdown of skeletal muscle, causing leakage of muscular contents into the circulation [11]. It is characterized by serum CK at least 10 times the upper limit of normal [12]. Clinical features occur over hours to days [13] and can range from asymptomatic CK elevation and myalgias to lifethreatening conditions such as electrolyte abnormalities, cardiac arrhythmias and renal failure [12]. Inherited causes include defects in cellular metabolism while acquired causes include substance abuse, trauma, medications and seizures [12]. Influenza is one of the most common viral causes [2]. However, clinicians need to suspect inherited disorders when associated with recurrence, positive family history or exercise intolerance.

During the literature review, we found a few reported cases of COVID-19 associated rhabdomyolysis in adults [2-8]. In three of these cases, with COVID-19 associated rhabdomyolysis, the patients were above 65 years of age and also developed acute kidney injury (AKI) with elevated creatinine $[3,4,6]$. For the other two cases, the patients were below 50 years of age, but had an associated AKI [5,7]. There was one case of a 38year-old male with COVID-19 associated rhabdomyolysis with normal renal function, however, his peak CK was only $42,670 \mathrm{U} / \mathrm{L}$ [8]. In pediatrics, there was a case of a 16-year-old male who presented with rhabdomyolysis, was diagnosed with COVID-19 and had a CK level over 400,000 [10]. However, he had a worsening renal function and eventually became anuric [10]. To our knowledge, there have been no cases of COVID-19 presenting with severe rhabdomyolysis with creatine kinase $>500,000 \mathrm{U} / \mathrm{L}$ with a normal renal function in a young adult. Interestingly, he also presented without the progressive pulmonary symptoms associated with COVID-19. 
Our report has limitations as it lacks a confirmed etiology of the rhabdomyolysis. We did not evaluate viral causes such as HIV, Epstein Barr virus (EBV) and cytomegalovirus (CMV). Further genetic testing would be required to identify inherited disorders predisposing him to viral infection associated rhabdomyolysis. Our patient, being young and not in acute respiratory distress syndrome (ARDS), tolerated aggressive hydration. However, the treatment of rhabdomyolysis in COVID-19 patients can be challenging, as aggressive hydration can worsen respiratory function, especially if the patient has heart failure or ARDS [3].

\section{Conclusions}

Rhabdomyolysis can be a life-threatening complication that has a high morbidity and mortality. It can present as a complication of viral infections and is also associated with COVID-19 among all age groups. Physicians need to be aware of the multifaceted presentations of COVID-19 and have rhabdomyolysis in the differential diagnosis. Treatment focuses on aggressive fluid hydration. However, this can be challenging and is limited by the patient's respiratory status and cardiac history.

\section{Additional Information \\ Disclosures}

Human subjects: Consent was obtained by all participants in this study. Conflicts of interest: In compliance with the ICMJE uniform disclosure form, all authors declare the following: Payment/services info: All authors have declared that no financial support was received from any organization for the submitted work. Financial relationships: All authors have declared that they have no financial relationships at present or within the previous three years with any organizations that might have an interest in the submitted work. Other relationships: All authors have declared that there are no other relationships or activities that could appear to have influenced the submitted work.

\section{References}

1. Huang C, Wang Y, Li X, et al.: Clinical features of patients infected with 2019 novel coronavirus in Wuhan, China. Lancet. 2020, 395:497-506. 10.1016/S0140-6736(20)30183-5

2. Jin M, Tong Q: Rhabdomyolysis as potential late complication associated with COVID-19. Emerg Infect Dis. 2020, 26:1618-1620. 10.3201/eid2607.200445

3. Suwanwongse K, Shabarek N: Rhabdomyolysis as a Presentation of 2019 Novel Coronavirus Disease . Cureus. 2020, 12:e7561. 10.7759/cureus.7561

4. Chan KH, Farouji I, Abu Hanoud A, Slim J: Weakness and elevated creatinine kinase as the initial presentation of coronavirus disease 2019 (COVID-19). Am J Emerg Med. 2020, 38:1548.e1-1548.e3. 10.1016/j.ajem.2020.05.015

5. Husain R, Corcuera-Solano I, Dayan E, Jacobi AH, Huang M: Rhabdomyolysis as a manifestation of a severe case of COVID- 19: a case report. Radiol Case Rep. 2020, 15:1633-1637. 10.1016/j.radcr.2020.07.003

6. Valente-Acosta B, Moreno-Sanchez F, Fueyo-Rodriguez O, Palomar-Lever A: Rhabdomyolysis as an initial presentation in a patient diagnosed with COVID-19. BMJ Case Rep. 2020, 13:e236719. 10.1136/bcr-2020236719

7. Mukherjee A, Ghosh R, Aftab G: Rhabdomyolysis in a patient with coronavirus disease . Cureus. 2019, 12:e8956. 10.7759/cureus.8956

8. Zhang Q, Shan KS, Minalyan A, O'Sullivan C, Nace T: A rare presentation of Coronavirus Disease 2019 (COVID-19) induced viral myositis with subsequent rhabdomyolysis. Cureus. 2020, 12:e8074. 10.7759/cureus.8074

9. Gefen AM, Palumbo N, Nathan SK, Singer PS, Castellanos-Reyes LJ, Sethna CB: Pediatric COVID-19associated rhabdomyolysis: a case report. Pediatr Nephrol. 2020, 35:1517-1520. 10.1007/s00467-020-046170

10. Samies NL, Pinninti S, James SH: Rhabdomyolysis and acute renal failure in an adolescent with COVID-19 . J Pediatric Infect Dis Soc. 2020, 10.1093/jpids/piaa083

11. Sauret JM, Marinides G, Wang GK: Rhabdomyolysis. Am Fam Physician. 2002, 65:907-913.

12. Zutt R, van der Kooi AJ, Linthorst GE, Wanders RJ, de Visser M: Rhabdomyolysis: review of the literature. Neuromuscul Disord. 2014, 24:651-659. 10.1016/j.nmd.2014.05.005

13. Nance JR, Mammen AL: Pediatric COVID-19-associated rhabdomyolysis: a case report. Pediatr Nephrol. 2020, 35:1517-1520. 10.1007/s00467-020-04617-0 